\title{
Future changes in monsoon duration and precipitation
} using CMIP6

\author{
Suyeon Moon (iD $^{1,2}$ and Kyung-Ja Ha (iD) ${ }^{1,2,3 凶}$
}

Future change in summertime rainfall under a warmer climate will impact the lives of more than two-thirds of the world's population. However, the future changes in the duration of the rainy season affected by regional characteristics are not yet entirely understood. We try to understand changes in the length of the rainy season as well as the amounts of the future summertime precipitation, and the related processes over regional monsoon domains using phase six of the Coupled Model Intercomparison Project archive. Projections reveal extensions of the rainy season over the most of monsoon domains, except over the American monsoon. Enhancing the precipitation in the future climate has various increasing rates depending on the subregional monsoon, and it is mainly affected by changes in thermodynamic factors. This study promotes awareness for the risk of unforeseen future situations by showing regional changes in precipitation according to future scenarios.

npj Climate and Atmospheric Science (2020)3:45 ; https://doi.org/10.1038/s41612-020-00151-w

\section{INTRODUCTION}

Monsoon systems are characterized by wind reversals and changes in moisture supply owing to the strong seasonal contrast between land and ocean temperatures ${ }^{1-3}$. More than two-thirds of the world's population is concentrated in the global monsoon (GM) region. Consequently, changes in global land monsoon precipitation will affect a large number of people who rely on monsoonal rainfall to sustain agriculture, industrial water demands, and social activities ${ }^{4}$. Understanding how the characteristics of monsoon precipitation will change in the future is a crucial challenge, not only for climate science but also for the life of people globally.

The fourth and fifth assessment reports of the Intergovernmental Panel on Climate Change (IPCC) repeatedly stated, that the understanding of future climate change remains considerably affected by uncertainties in terms of precipitation estimates ${ }^{5,6}$. The Clausius-Clapeyron (C-C) relationship implies that an increase in global temperature will enhance precipitation ${ }^{7}$. An increase in water holding capacity of the atmosphere with temperature occurs at a rate given by approximately $7 \%$ per $1{ }^{\circ} \mathrm{C}$ warming $\left(\%{ }^{\circ} \mathrm{C}^{-1}\right)$. Future climate projections suggest an increase in GM precipitation due to an increasing amount of water vapor in the atmosphere under global warming ${ }^{7-9}$. Furthermore, previous studies have shown that the GM domain will be expanded as well as the rainfall intensity also increases in a warming climate $e^{10-12}$.

To fully understand the future changes in the GM, a study from a regional perspective is required. The multimodel projections of precipitation mostly show a rich-gets-richer pattern in terms of monsoon intensity, albeit with regional differences ${ }^{3,7,12}$. Individual monsoon regions have different temperature-precipitation relationships. Individual atmosphere-ocean-land interactions, land-ocean configurations, orography, and diverse monsoon variations across individual regions bring regional characteristics of GM estimations ${ }^{13-15}$. We need to see how much precipitation increase by monsoon regions to prepare for appreciating policies for climate change. Also, the onset date, together with the retreat date, changes every year, has vital importance for millions of farmers around the world. A recent study showed that East Asian and Indian monsoons will be the most affected in this respect in the future using CMIP6 simulations ${ }^{3}$. The Asian monsoon domain has been widely investigated in the literature, whereas more global studies are still required.

The future projections of regional monsoons remain largely uncertain and need more careful investigations, as monsoon has a strong sensitivity to global warming. We assess to what extent the summertime precipitation will increase for a given temperature rise owing to global warming, and identify the main process contributing to the changes in precipitation using three future projections in the 14 CGCMs that participated in phase six of the Coupled Model Intercomparison Project (CMIP6) archive (Supplementary Table 1). More specifically, we compare four runs: the historical run from 1995 to 2014; the Shared Socioeconomic Pathway (SSP) 1-2.6 scenario (hereafter mentioned as SSP1-2.6); SSP2-4.5; and SSP5-8.5 runs in the near term (2021-2040), mid term (2041-2060), and long term $(2081-2100)^{16}$. Our ultimate goal is to quantify changes in precipitation over individual monsoon domains so as to assess the future precipitation-related risk in each region.

\section{RESULTS}

Changes in summer precipitation under a warmer climate

The relationship between the water-holding capacity of the atmosphere and the temperature provides useful information for climate predictions, albeit with large uncertainties ${ }^{17}$. The GM precipitation is a key variable of the global hydrological cycle. The variability in GM rainfall is highly correlated (>0.9) with the variability in global average precipitation, so it may serve as a proxy of fluctuation in global mean precipitation. We describe the future changes in summertime precipitation and annual air temperature over the monsoon domain globally (Fig. 1). In terms of emission scenarios and future terms, the changing rate of precipitation is distinct. Overall, the rates of precipitation increase are linear with varying slopes depending on temperature increase.

${ }^{1}$ Center for Climate Physics, Institute for Basic Science, Busan 46241, South Korea. ${ }^{2}$ Department of Climate System, Pusan National University, Busan 46241, South Korea.

${ }^{3}$ BK21 School of Earth and Environmental Systems, Pusan National University, Busan 46241, South Korea. ${ }^{凶}$ email: kjha@pusan.ac.kr 
GM

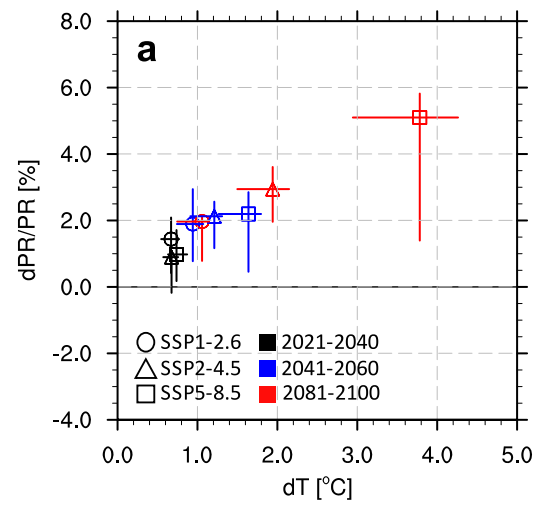

NHM

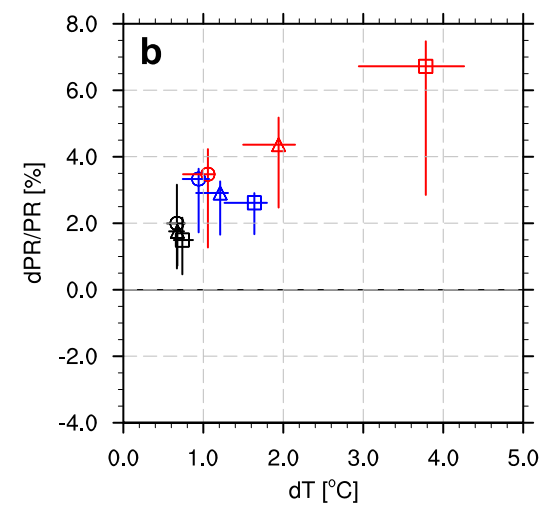

SHM

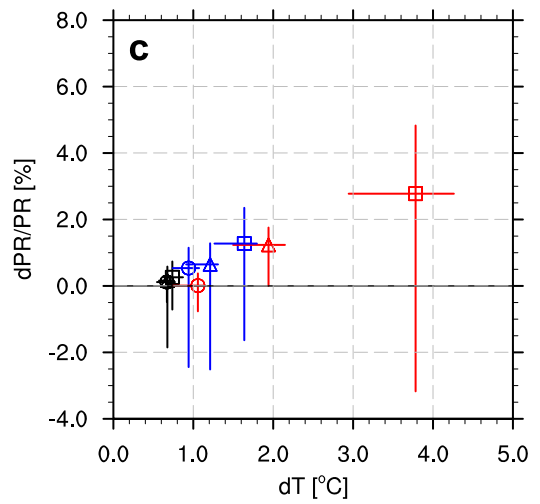

Fig. 1 Future changes in precipitation and global temperature over the global monsoon domain. a-c Median of multiple-model percentile changes in summertime precipitation (\%) and global mean temperature $\left({ }^{\circ} \mathrm{C}\right)$ over: a the global monsoon (GM), b the Northern Hemisphere monsoon (NHM), and c the Southern Hemisphere monsoon (SHM) domains. Changes are relative to the present period (1995-2014). Circles, triangles, and squares indicate three different future scenarios (SSP126, SSP245, and SSP585, respectively). The colors refer to the individual future periods: near term (black; 2021-2040), mid term (blue; 2041-2060), and long term (red; 2081-2100). Error bars show the range between the 25 th and 75 th percentiles.

The GM precipitation will increase under a warm climate; however, the predicted rate is smaller than that expected from the $\mathrm{C}-\mathrm{C}$ relationship ${ }^{18}$. The higher emission scenario is expected a larger increase both temperature and precipitation in the long term: approximately $2.7^{\circ} \mathrm{C}$ for temperature and $3.1 \%$ for precipitation between the SSP1-2.6 and SSP5-8.5. As regards the difference in the rate of increase in precipitation by period, the SSP1-2.6 scenario exhibits the largest increasing rate between in the mid and in the near term. It seems that the characteristics of low emission SSP scenarios. The SSP1-2.6 scenario already reaches $2.6 \mathrm{Wm}^{-2}$ in the near term and declines or persists within the $21 \mathrm{st}$ century ${ }^{16}$.

Note that changes in summertime precipitation show very large differences between the Northern Hemisphere monsoon (NHM) and the Southern Hemisphere monsoon (SHM). Precipitation over the $\mathrm{NHM}$ is predicted to increase as temperature increases in all future scenarios and periods. While the NHM precipitation is expected to increase by $6.7 \%$ (Fig. 1b), the SHM precipitation is expected to increase only by $2.8 \%$ (Fig. 1C) under a $3.8^{\circ} \mathrm{C}$ global warming in the long term according to the SSP5-8.5 scenario (Supplementary Table 2). Moreover, the uncertainty associated with these changes in precipitation is smaller for the NHM than for the SHM.

When we consider the relative change in precipitation over the temperature change for the NHM, we observe a steeper trend for the SSP1-2.6 $\left(4 \%{ }^{\circ} \mathrm{C}^{-1}\right)$ than for the SSP2-4.5 $\left(2.1 \%{ }^{\circ} \mathrm{C}^{-1}\right)$ and SSP5-8.5 $\left(1.8 \%{ }^{\circ} \mathrm{C}^{-1}\right)$ scenario, even though the total relative change in SSP1-2.6 is the lowest among the scenarios. Over the $\mathrm{SHM}$, there is no significant relationship between precipitation and temperature in SSP1-2.6. However, the increasing rates of summertime precipitation with the global temperature rise are similar under the SSP2-4.5 and SSP5-8.5 with $0.8 \%{ }^{\circ} \mathrm{C}^{-1}$. The CMIP5 predicts that the NHM precipitation will increase by $3.1 \%{ }^{\circ} \mathrm{C}^{-1}$, while the SHM precipitation will insignificantly decrease under the representative concentration pathway 4.5 (RCP 4.5) scenario $^{12}$. Although the increasing rates of summertime precipitation are slightly different, the overall patterns match well, showing that the NHM precipitation will intensify more than that of the SHM.

Changes in projected precipitation are largely uncertain over the SHM. Moreover, the response of individual regional monsoons to climate change is expected to diversify because of various forcings ${ }^{14,19}$. To overcome these limitations of future projection such as localization and various response to the rising temperature, we conduct a regional analysis of precipitation changes over nine monsoon regions (Fig. 2). We focus on the median value of precipitation to obtain more reliable future change estimations. Although the sensitivity of precipitation with the global temperature rise is generally low compared with other monsoon domains over the African monsoon regions, the projected changes show distinct patterns over both the North African monsoon (NAF) and South African monsoon (SAF) regions. The precipitation over the NAF is mostly expected to increase, with more than $75 \%$ of the models agreeing on such increase. On the other hand, the precipitation over the SAF is expected to decrease $\left(-0.6 \%{ }^{\circ} \mathrm{C}^{-1}\right)$ in the near term, but slightly increase $\left(+0.6 \%{ }^{\circ} \mathrm{C}^{-1}\right)$ in the long term as the average values of three scenarios.

Most of the monsoon regions, and especially the Indian monsoon (IND) region, will see an increase in the summertime precipitation in the future. A previous study showed that the South Asian monsoon will carry $5 \%$ more rainfall under the RCP 4.5 warming scenario ${ }^{20}$. Here, we divided the South Asian monsoon into IND and Indo-China Peninsula monsoon (ICP) to identify their respective regional characteristics, because the starting date and occurrence mechanism of these two monsoons are different from each other ${ }^{3,11,21}$. The percentage change in precipitation per one-degree Celsius warming in the long term SSP5-8.5 scenario is higher over IND (+6\%) than over ICP (+3.6\%). Likewise, future monsoon projections from the CMIP6 models show an increase in precipitation in the East Asian monsoon (EA) region under all scenarios and periods with high confidence. The largest increase is observed under the SSP12.6 scenario owing to the slight global temperature increase $\left(+0.7^{\circ} \mathrm{C}\right)$; however, the spread across the models is small under the SSP5-8.5 scenario in the long term. In the CMIP5 RCP4.5 scenario outputs, the EA summer precipitation is predicted to increase by $6.4 \%{ }^{\circ} \mathrm{C}^{-1}$ in the late future ${ }^{20}$. This rate is higher than that yielded by the CMIP6 projections $\left(5.6 \%{ }^{\circ} \mathrm{C}^{-1}\right)$, indicating that the precipitation over the EA in the CMIP6 simulations is less sensitive to temperature compared to the CMIP5 simulations.

The western-North Pacific monsoon (WNP), which is an oceanic monsoon, shows an increasing rate of summer rainfall across most model performances. The median rainfall increase over the WNP is relatively steady at around $2.1 \%{ }^{\circ} \mathrm{C}^{-1}$. Regardless of the scenarios, the Australian monsoon (AU) precipitation will slightly increase by about $2 \%{ }^{\circ} \mathrm{C}^{-1}$ in the long term with high confidence. Note that the long term precipitation over the North American monsoon (NAM) shows a decreasing trend $\left(-0.2 \%{ }^{\circ} \mathrm{C}^{-1}\right)$ under the SSP5-8.5 scenario. The differences across the scenarios for the sensitivity of future precipitation to increased temperatures over the NAM are 

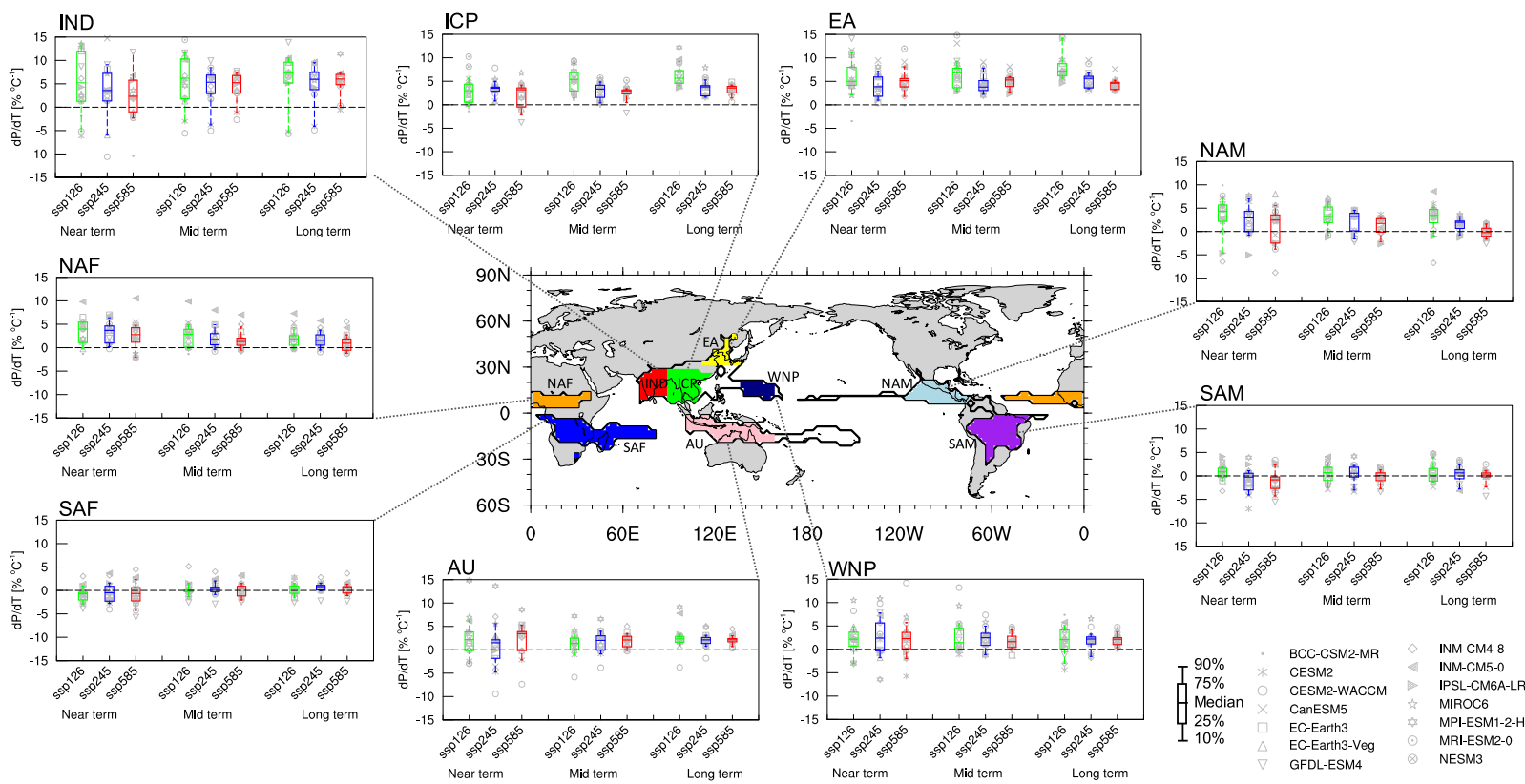

Fig. 2 Percentage changes in precipitation per one-degree Celsius of global warming in CMIP6 future scenarios. The boxplots represent the percentage changes in summertime precipitation per one-degree Celsius $\left(\%{ }^{\circ} \mathrm{C}^{-1}\right)$ according to the CMIP6 models for three future scenarios relative to near-term, mid-term, and long-term periods over the Northern African (NAF), Southern African (SAF), Indian (IND), IndoChina Peninsula (ICP), East Asian (EA), western-North Pacific (WNP), Australian (AU), Northern American (NAM), and Southern American (SAM) monsoon domains. Gray symbols indicate the individual CMIP6 models whereas the boxes indicate the spread (from the 25th to the 75th percentile, with the center lines representing the median) of the CMIP6 models.

discussed later. The low percentage change $\left(< \pm 1 \%{ }^{\circ} \mathrm{C}^{-1}\right)$ is exhibited over the South American monsoon (SAM).

The moisture supply is a key factor for increasing precipitation in the future. The high emission scenario could lead to the relatively low increasing rate of future precipitation due to the limitation of sufficient atmospheric moisture supply (Fig. 2). In summary, most of the regional summertime precipitations are projected to increase, except for the SAF and SAM region in the near term and the NAM in the long term under the SSP5-8.5 scenario. Furthermore, precipitation is expected to increase at a higher rate in the Asian monsoon regions compared to other regions.

Projected changes in the duration of the rainy season

In response to an increase in global air temperature, the expected increase in summertime rainfall at a regional scale has the potential to change the rainy season ${ }^{3,11}$. According to various factors potentially controlling the monsoon seasons, such as the land-ocean configuration, orography, and others, the changes in the length of the rainy season are expected to vary from region to region. The simulated future changes in the rainy season are shown in Fig. 3. The rainy season in the Asian monsoon region is projected to gradually and certainly lengthened in duration. The duration of the summer monsoon over IND and ICP might increase by more than three pentads in the future mainly owing to a delayed retreat. In contrast, the earlier onset over EA is the key factor of the predicted lengthening of the rainy season by 1.6 pentads under the SSP5-8.5 scenario, although the retreat of EA monsoon will slightly delay under SSP1-2.6 and SSP2-4.5 sceanrios ${ }^{3}$. These results are consistent with those of many studies that illustrated various behaviors in the subregional Asian monsoon domain using CMIP3, CMIP5, and CMIP6 models $3,11,12,20,22-24$.

Shifted and longer rainy seasons are projected over SAF. A longer monsoon period over $\mathrm{AU}(+1.3$ pentads) is expected during future periods under the SSP5-8.5 scenario, albeit for different reasons, namely a delayed retreat in the mid term, and an earlier onset in the long term. With regards to the future periods (e.g., NAF) and scenarios (e.g., WNP), the future rainy season is captured with an inconsistent response. Over WNP, the agreement across the simulations is poor as the models illustrate different responses in terms of changes in duration. In contrast to most of the monsoon domains, a shorter rainy season is projected over NAM (up to -3 pentads) and SAM (up to -1.2 pentads) due to the advanced retreat and delayed onset in the long term, respectively.

Interestingly, the duration of the rainy season has a highly positive correlation with the relative increase in the amount of precipitation per one-degree temperature increase (Fig. 4). The regions in which the relative precipitation increase is expected to be the largest in the future will also be characterized by longer monsoon seasons. This suggests that a longer rainy season might contribute to the increased amount of rainfall or vice versa. This should be accounted for in risk assessments as it implies that longer rainy seasons might affect people's lives in additional ways than those evaluated thus far. In the following section, we evaluate how thermodynamic and dynamic factors produce changes in precipitation, which are, in turn, indicative of changes in the hydrological cycle.

Contribution of the thermodynamic and dynamic terms

To elucidate how thermodynamic and dynamic factors influence the future changes in precipitation, we investigate the moisture budget equation during the summertime (Fig. 5). Most of the increase in precipitation can be explained by analyzing the structures related to the atmospheric moisture budget ${ }^{25-27}$. A robust feature simulated by the CMIP6 models is that the thermodynamic effect, which mainly originates from the increased 

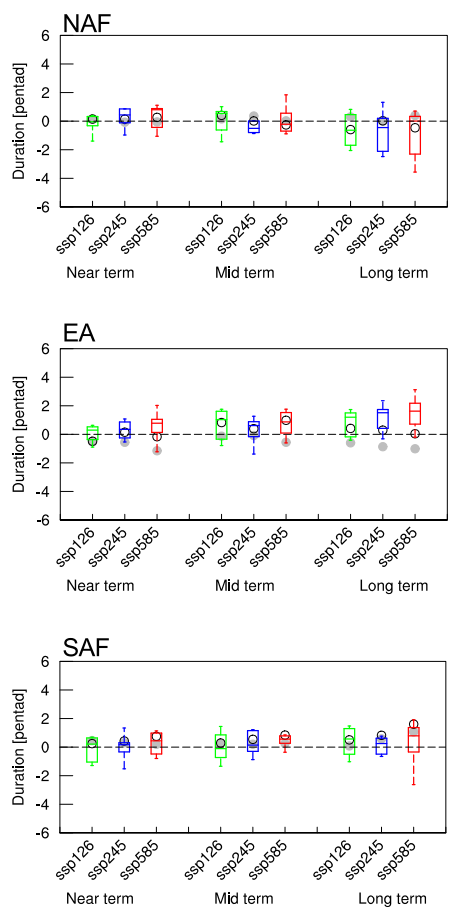
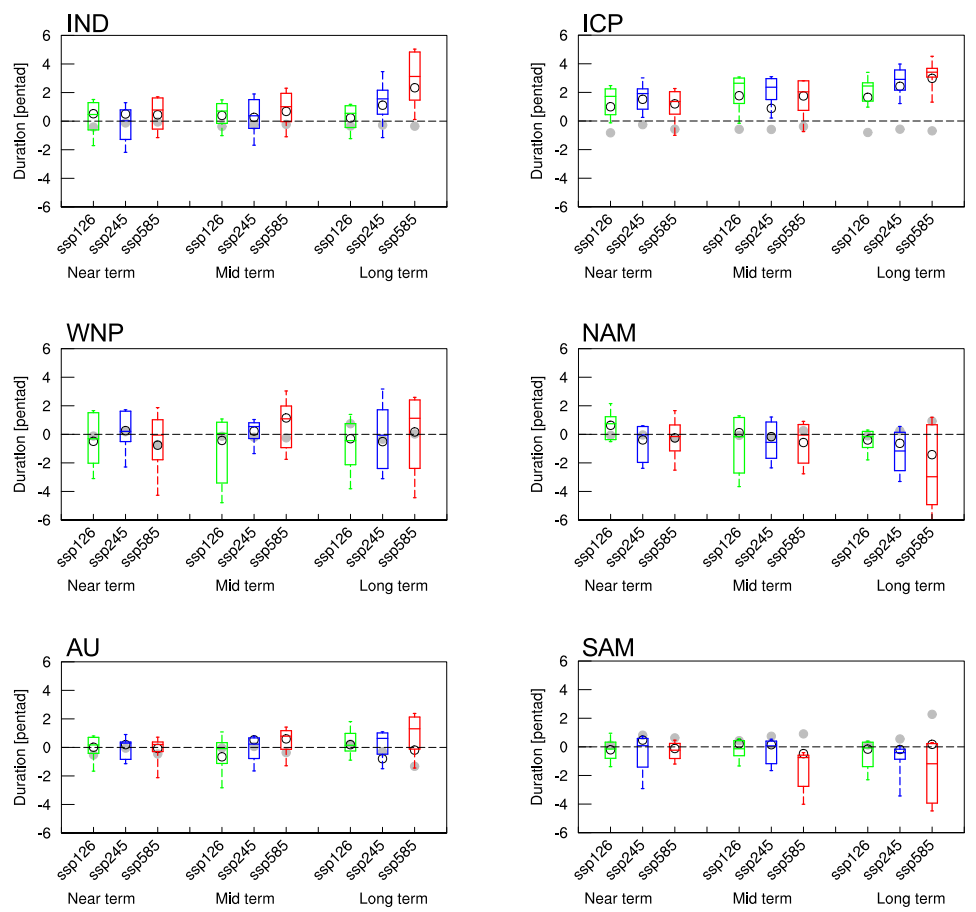

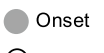

Retreat
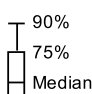

Median

$25 \%$

$\perp 10 \%$

Fig. 3 Changes in length of the rainy season over global monsoon regions. Future changes (unit: pentad) in onset (filled gray circle), retreat (black circle), and duration (box plot) for nine global monsoon domains. The boxes indicate the spread (from the 25th to the 75th percentile; center lines indicate the median) of the CMIP6 models.

SSP1-2.6

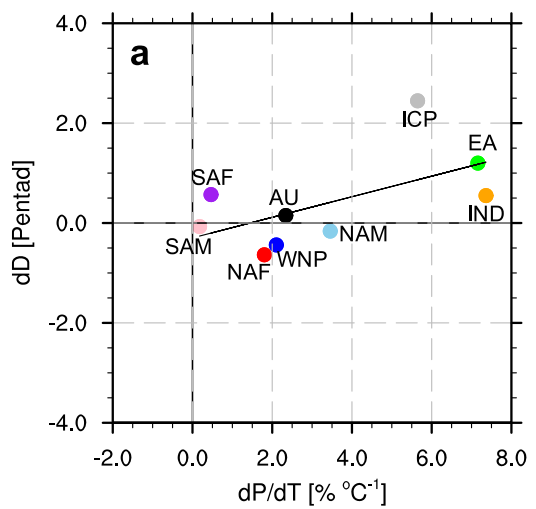

SSP2-4.5

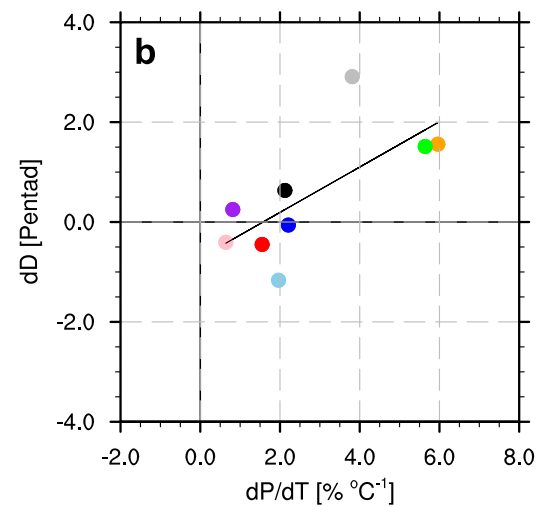

SSP5-8.5

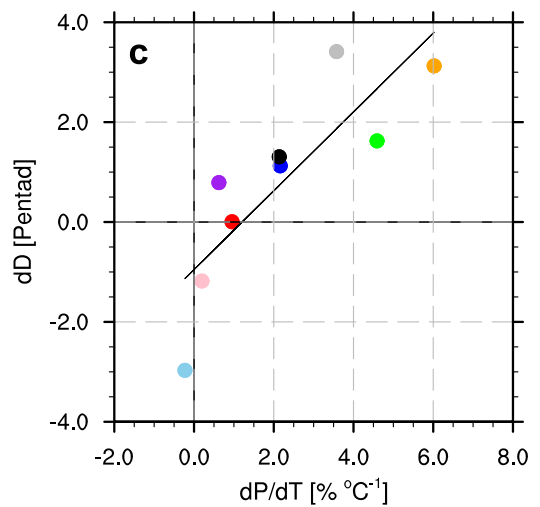

Fig. 4 Relationship between the changes in rainy season and changes in precipitation due to the increase in temperature. Individual dots indicate the regional monsoon domains in the long term (2081-2100) based on a SSP1-2.6, b SSP2-4.5, and c SSP5-8.5 scenarios. The lines depict the linear regression between the changes in duration and changes in precipitation according to the increasing temperature.

amount of water vapor, plays an important role in enhancing both the moisture convergence and evaporation, while the dynamic effect has a minor role ${ }^{27-29}$. The contribution of the thermodynamic and dynamic terms is similar across all future periods, with the largest changes projected in the long term (Fig. 5c).

The precipitation-minus-evaporation $(\mathrm{P}-\mathrm{E})$ term exhibits the largest changes over the Asian monsoon domain, particularly in ICP and IND. The dynamic (DY) and thermodynamic (TH) effects have opposite signs for future $\mathrm{P}-\mathrm{E}$ over the tropical region, in general $^{9,30}$. The positive $\mathrm{P}-\mathrm{E}$ over most of the monsoon domains is primarily due to the positive $\mathrm{TH}$ effect associated with the warming climate. The previous study has shown that the $\mathrm{TH}$ changes of mean moisture convergence are dominated by the greenhouse gases forcing, whereas the DY changes are mainly contributed by aerosol forcing under the RCP 8.5 scenario in
$\mathrm{CMIP}^{27}$. Interestingly, both TH and DY terms have a positive sign in $\mathrm{IND}^{26}$. In this region, the $\mathrm{TH}$ mainly leads to increased precipitation, with the DY also contributing to it. On the other hand, over the EA region, the DY term contributes to the summer precipitation, while $\mathrm{TH}$ plays against it. Although the previous studies have investigated that the $\mathrm{TH}$ plays a positive role in increasing precipitation over most of the monsoon domain under the CMIP5 simulations (Supplementary Fig. 1) ${ }^{9,15}$, CMIP6 projection shows the negative effect of $\mathrm{TH}$ on the rainfall over the EA domain. The negative TH effect over the EA domain is caused by the horizontal advection due to changes in specific humidity under the CMIP6 projection (Supplementary Fig. 2).

In the case of NAF, the result that future precipitation to global warming is largely explained by the enhancement of the TH effect is consistent with the prior study ${ }^{31}$. Note that the $\mathrm{P}-\mathrm{E}$ term over 

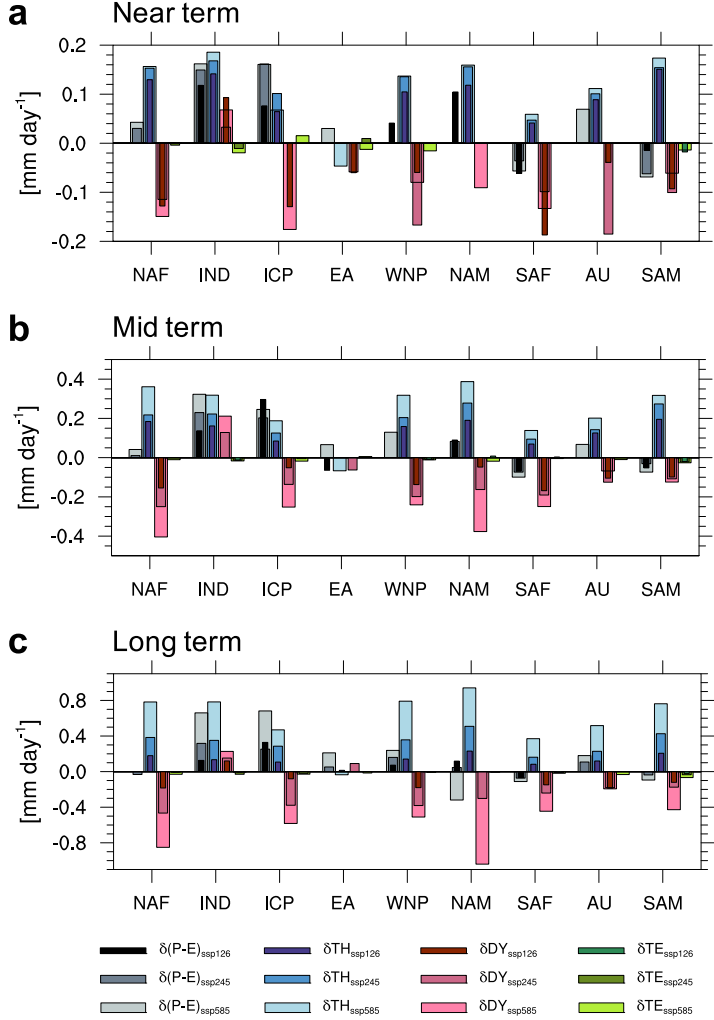

Fig. 5 Regionally averaged future changes of each term of the moisture budget equation. a-c Future changes of precipitation minus evaporation ( $\mathrm{P}-\mathrm{E}$; black), thermodynamic ( $\mathrm{TH}$; blue), dynamic (DY; red), and transient (TE; green) terms in the a near term (2021-2040), b mid term (2041-2060), and c long term (2081-2100) across regional monsoon regions. The width of the bar shows the future scenarios: SSP126 (narrow), SSP245 (middle), and SSP585 (wide). The shown bars indicate that more than two-thirds of the models agree on the sign of the change.

SAF and SAM implies a decrease in future precipitation, because the increase of evaporation is larger than that of precipitation (Figs. 2 and 5). Thus, it is evident that evaporation is also a key factor modulating the hydrological cycle: an increase in evaporation may result in a substantial increase in drought ${ }^{3}$. The $P-E$ term is modulated by spatial gradients of fractional changes in relative humidity ${ }^{30}$. If we only consider the land precipitation, the aridity, which reflects how the global land evaporative demand outpaces the precipitation increase under global warming, can be amplified by the feedbacks of drier soil ${ }^{32}$. As lots of forests are concentrated in SAF and SAM, further studies on the physiological effect of carbon dioxide concentrations on plant transpiration are also warranted $^{33}$.

Robust differences in $\mathrm{P}-\mathrm{E}$ changes across the scenarios are shown over the NAM. An increased $P-E$ is expected under SSP1-2.6 and SSP2-4.5 scenario, while the SSP5-8.5 scenario provides an opposite trend. Here, the DY term plays an important role in modulating the $\mathrm{P}-\mathrm{E}$. The large magnitude of the DY term under the SSP5-8.5 scenario turns the P-E term from positive to negative. Similarly, the CMIP5 projects that the rainfall over NAM will decrease in the long term under the RCP8.5 scenario, albeit with less confidence? ${ }^{9}$. In general, not only for the CMIP5 simulations but also for high-resolution atmospheric global climate model simulations show the $\mathrm{TH}$ is the primary factor of increasing monsoonal precipitation ${ }^{31,34}$. This study sheds light on the understanding of the future precipitation changes in the regional aspects by dividing the global monsoon into nine regional monsoon regions.

Effect of changes in convective precipitation

In addition to the expected changes in the amount of precipitation, we investigate how the type of precipitation is forecasted to change. The precipitation can be classified into convective precipitation $\left(P_{\text {conv }}\right)$ and stratiform precipitation $\left(P_{\text {strat }}\right)$. Changes in the trends of these two types may differ as the mechanisms that generate them are different. With respect to the daily $P_{\text {conv }}$ over the global monsoon domain, increasing values are expected for the Asian monsoon in the future (Supplementary Fig. 3). The $P_{\text {conv }}$ over the EA exhibits notable changes (up to $30 \%$ ) in the long term under the SSP5-8.5 scenario. The $P_{\text {conv }}$ is generally sensitive to the temperature increase ${ }^{35}$, particularly in the short time scales, and induces more extreme precipitation over $\mathrm{EA}^{36}$. These results suggest that extreme precipitation may be generated over EA in the future with high probability ${ }^{3}$. Over the extratropic regions such as EA, accounting for $P_{\text {conv }}$ explicitly can aid in the prediction of extreme rainfall.

As a consequence of the projected increase in $P_{\text {conv }}$ over most of the monsoon domains, the fraction of $P_{\text {conv }}\left(F_{\text {conv }}\right)$ also is expected to become larger than that in the present climate. Conversely, the $P_{\text {conv }}$ over NAM and NAF is projected to slightly decrease, even though those regions are located in the tropics. Although $P_{\text {conv }}$ is the dominant type of rainfall in the tropics, the models highlight some regional variability. Furthermore, by comparing the scenarios, it can be seen that $P_{\text {conv }}$ generally varies more under SSP1-2.6 than under SSP2-4.5. It is possible that the convection parameterization plays a role in the predicted increase in total precipitation under the SSP1-2.6 scenario.

\section{DISCUSSION}

The accurate knowledge of climate change is important to cope with the probability of natural disasters. We show the individual changes in precipitation per $1{ }^{\circ} \mathrm{C}$ global warming based on the analysis of CMIP6 in terms of the global and local summertime precipitation. The state-of-the-art CMIP6 climate models project that NHM rainfall will increase more than that of SHM with high confidence, and Asian monsoon projects highly enhanced precipitation under the $1{ }^{\circ} \mathrm{C}$ of warming. The summertime rainfall will be enhanced in response to a stronger thermodynamic effect, while the atmospheric circulation should weaken over most of the regional monsoon domains. Static stability could explain why the increasing rate of precipitation is smaller than that predicted with the $\mathrm{C}-\mathrm{C}$ approximation. A warm atmosphere tends to strengthen the static stability, weakening the vertical motion, and resulting in less precipitation ${ }^{12,20}$. Increasing static stability is prominent in both the lower and the upper atmosphere (Supplementary Fig. 4). The latter has large differences in the response to the different emission scenarios. Most of the monsoon domains are projected to exhibit stabilized by $35 \%$ in the long term relative to the present value under the SSP5-8.5. As the low-level static stability will decrease up to $10 \%$, with less interscenario differences, it is likely that the smaller-than-expected increase in precipitation is mostly governed by the upper-level static stability.

We also attempted to provide an insight into change in the duration of the rainy season. The extension of the rainy season is projected over most of the monsoon domains. For example, changes in retreat (onset) are the key factors to lengthening the monsoon season over IND, ICP, and SAF (ICP, EA, SAF, and AU) in the long term under the SSP5-8.5 scenario, respectively. Shortening the rainy season over American monsoon is one of the notable points in this study. As the length of the rainy season is highly affected by the local topography, high-resolution modeling 
simulation could improve the prediction skill for a season change. This study motivates further research aimed at improving the convection parameterization and identifying the response of $P_{\text {strat }}$. The decline of the moisture lapse-rate is expected to modulate the change in $P_{\text {strat }}$. In addition, the role of the land system concerning evaporation, future land-use change, and shifting vegetation patterns on the hydrological cycle should be investigated with regard to land monsoon rainfall. Finally, we should pay attention to possible feedbacks under warmer climate and recognize the potential risk of exceeding unknown thresholds, such as tipping points ${ }^{37,38}$. To properly assess future changes in precipitation, we must ensure that the projected changes in the regional monsoons can be interpreted in terms of the physics involved, which must, therefore, be understood. Our confidence in the future projection of summertime precipitation using various emission scenarios is likely to improve the understanding of the impacts of a warmer climate in the future.

\section{METHODS}

\section{Data collection from the CMIP6 archive}

We use monthly and daily precipitation, convective precipitation, and 2-m air temperature data for the historical period (1995-2014) and a future period (2015-2100) using climate projections under the Shared Socioeconomic Pathway (SSP) 1-2.6 (SSP1-2.6), 2-4.5 (SSP2-4.5), and 5-8.5 (SSP5-8.5) scenarios in the CMIP6 archive. The first number in the SSP label indicates the assumed shared socio-economic pathway, whereas the second number indicates the global effective radiative forcing by 2100 . Further information on the SSP scenarios is available in O'Neill et al. ${ }^{16}$. Details of the used climate models are given in Table S1. Only one member of each model is used. We identify three future terms, which we name as the near term (2021-2040), mid term (2041-2060), and long term (2081-2100). The CMIP6 CGM historical simulations are evaluated against the pentad precipitation from the Global Precipitation Climatology Project (GPCP) dataset ${ }^{39}$ and the ERA-Interim data ${ }^{40}$ from the European Center or Medium-Range Weather Forecasts (ECMWF). All the models and observations are interpolated in a $2.5^{\circ} \times 2.5^{\circ}$ grid prior to performing the analysis. Because this study focuses on the change in summertime precipitation, the target season spans May to September (MJJAS) for the Northern Hemisphere (NH) and November to March (NDJFM) for the Southern Hemisphere $(\mathrm{SH})$. The Taylor diagram over the global domain $\left[30^{\circ} \mathrm{S}-60^{\circ} \mathrm{N}\right.$, $\left.0^{\circ}-360^{\circ} \mathrm{E}\right]$ for the summertime precipitation and air temperature shows the quantified model performance skill (Supplementary Fig. 5). The pattern correlation coefficients between the simulated precipitation and GPCP data range between 0.77 and 0.89 . In the case of air temperature, the spatial correlation coefficients range from 0.89 to 0.98 . The key features of the global summertime precipitation and air temperature are well captured in the CMIP6 projections.

\section{Definition of the monsoon domain and rainy season}

The monsoon domain is defined as the location where the annual amplitude of precipitation is greater than $2 \mathrm{~mm}$ day $^{-1}$ and the amplitude of the annual cycle of precipitation is ten times larger than that of the semiannual cycle, following the definition of $\mathrm{Ha}$ et al. ${ }^{3}$. The defined global summertime monsoon domain is decomposed into nine regional monsoon domains, as shown in Fig. 2, namely the North African monsoon (NAF), South African monsoon (SAF), Indian monsoon (IND), Indo-China Peninsula monsoon (ICP), East Asian monsoon (EA), western-North Pacific monsoon (WNP), Australian monsoon (AU), North American monsoon (NAM), and South American monsoon (SAM). The four Asian monsoon domains are divided based on the homogeneity of the onset of summer monsoon to identify the changes in the rainy season ${ }^{3}$.

Analyzing the rainy season is the same as $\mathrm{Ha}$ et al. ${ }^{3}$ method. They modified the definition of Wang and $\mathrm{LinHo}^{2}$, who used the onset and retreat of monsoon using the sum of the first 12 harmonics of precipitation by adding the duration condition. The advantage of this definition is that the same onset and retreat threshold can be used regardless of location. The Previous study ${ }^{3}$ investigated the representative rainfall for the monsoon domains by using the area-averaged precipitation. However, here we have used the area mean of grid-by-grid calculation of onset, retreat, and duration over the individual regional monsoon domains to consider the features of each point well.

\section{Moisture budget equation}

To identify the cause of the changing future precipitation over individual regional monsoon domains, the moisture budget equation is used, as in Seager et al. ${ }^{41}$ :

$\delta P-\delta E=\delta \mathrm{TH}+\delta \mathrm{DY}+\delta \mathrm{TE}+\mathrm{Res}$,

$\delta \mathrm{TH}=-\frac{1}{\rho_{\mathrm{wg}}} \int_{100 \mathrm{hPa}}^{\overline{p_{\text {shis }}}} \nabla \cdot\left(\overline{\boldsymbol{u}_{\text {his }}}[\delta \bar{q}]\right) d p$,

$\delta \mathrm{DY}=-\frac{1}{\rho_{\mathrm{wg}}} \int_{100 \mathrm{hPa}}^{\overline{p_{\mathrm{shis}}}} \nabla \cdot\left([\delta \overline{\boldsymbol{u}}] \overline{q_{\mathrm{his}}}\right) d p$

$\delta \mathrm{TE}=-\frac{1}{\rho_{\mathrm{wg}}} \int_{100 \mathrm{hPa}}^{\overline{s_{\mathrm{his}}}} \nabla \cdot \delta\left(\overline{u^{\prime} q^{\prime}}\right) d p$,

$\delta(\cdot)=(\cdot)_{\text {fut }}-(\cdot)_{\text {his }}$,

where $P$ is the precipitation and $E$ is the evaporation from the surface. The thermodynamic $(\delta \mathrm{TH})$ term is only influenced by changes in specific humidity and mean circulations. The altered circulation and mean specific humidity affect the dynamic $(\delta D Y)$ term. The transient eddy $(\delta T E)$ term is related to the changes in eddy flux, and Res indicates the residual term; $\boldsymbol{u}$ is the horizontal vector wind, $q$ is the specific humidity, $P_{\mathrm{s}}$ is the surface pressure, $\rho_{w}$ is the density of water, and $g$ is the gravitational constant. The overbar indicates the climatological monthly mean and the prime indicates the departure from the climatological monthly mean. Subscripts his and fut indicate historical and future values, respectively. As we considered three future periods (near-term, mid-term, and long-term), the fut value changes with the considered period.

\section{DATA AVAILABILITY}

The ERA-Interim data can be downloaded from the website: http://apps.ecmwf.int/ datasets/. The GPCP data was downloaded from https://rda.ucar.edu/datasets/ ds728.3/. All CMIP6 model data are available at: https://esgf-node.llnl.gov/search/ cmip6/.

Received: 8 July 2020; Accepted: 23 October 2020; Published online: 23 November 2020

\section{REFERENCES}

1. Liu, B. et al. Asian summer monsoon onset barrier and its formation mechanism. Clim. Dyn. 45, 711-726 (2015).

2. Wang, B. \& LinHo Rainy season of the Asian-Pacific Summer Monsoon. J. Clim. 15, 386-398 (2002).

3. Ha, K.-J., Moon, S., Timmermann, A. \& Kim, D. Future changes of summer monsoon characteristics and evaporative demand over Asia in CMIP6 simulations. Geophys. Res. Lett. 47, e2020GL087492 (2020).

4. Ueda, $H$. et al. Combined effects of recent Pacific cooling and Indian Ocean warming on the Asian monsoon. Nat. Commun. 6, 1-8 (2015).

5. Solomon, S. et al. Climate Change 2007: IPCC Fourth assessment report (AR4). Cambridge Press 996 (2007).

6. IPCC. Climate Change 2014: Synthesis Report. Contribution of Working Groups I, II and III to the Fifth Assessment Report of the Intergovernmental Panel on Climate Change 151 (2014).

7. Held, I. M. \& Soden, B. J. Robust responses of the hydrological cycle to global warming. J. Clim. 19, 5686-5699 (2006).

8. Ueda, H., Iwai, A., Kuwako, K. \& Hori, M. E. Impact of anthropogenic forcing on the Asian summer monsoon as simulated by eight GCMs. Geophys. Res. Lett. 33, L06703 (2006).

9. Endo, H. \& Kitoh, A. Thermodynamic and dynamic effects on regional monsoon rainfall changes in a warmer climate. Geophys. Res. Lett. 41, 1704-1711 (2014).

10. Sperber, K. R. et al. The Asian summer monsoon: An intercomparison of CMIP5 vs. CMIP3 simulations of the late 20th century. Clim. Dyn. 41, 2711-2744 (2013).

11. Moon, S. \& Ha, K. J. Temperature and precipitation in the context of the annual cycle over Asia: model evaluation and future change. Asia Pac. J. Atmos. Sci. 53, 229-242 (2017).

12. Lee, J. Y. \& Wang, B. Future change of global monsoon in the CMIP5. Clim. Dyn. 42, 101-119 (2014). 
13. Lee, E. J., Ha, K. J. \& Jhun, J. G. Interdecadal changes in interannual variability of the global monsoon precipitation and interrelationships among its subcomponents. Clim. Dyn. 42, 2585-2601 (2014).

14. Turner, A. G. \& Annamalai, H. Climate change and the South Asian summer monsoon. Nat. Clim. Change 2, 587-595 (2012).

15. Sharmila, S., Joseph, S., Sahai, A. K., Abhilash, S. \& Chattopadhyay, R. Future projection of Indian summer monsoon variability under climate change scenario: an assessment from CMIP5 climate models. Glob. Planet. Change 124, 62-78 (2015).

16. Neill, B. C. O. et al. The Scenario Model Intercomparison Project (ScenarioMIP) for CMIP6. Geosci. Model Dev. 9, 3461-3482 (2018).

17. Zhang, X., Zwiers, F. W., Li, G., Wan, H. \& Cannon, A. J. Complexity in estimating past and future extreme short-duration rainfall. Nat. Geosci. 10, 255-259 (2017).

18. Allen, M. R. \& Ingram, W. J. Constraints on future changes in climate and the hydrologic cycle. Nature 419, 228-232 (2002).

19. Kitoh, A. et al. Monsoons in a changing world: a regional perspective in a global context. J. Geophys. Res. Atmos. 118, 3053-3065 (2013).

20. Wang, B., Yim, S. Y., Lee, J. Y., Liu, J. \& Ha, K. J. Future change of Asian-Australian monsoon under RCP 4.5 anthropogenic warming scenario. Clim. Dyn. 42, 83-100 (2014).

21. Moon, S. \& Ha, K. Early Indian summer monsoon onset driven by low soil moisture in the Iranian desert. Geophys. Res. Lett. 46, 1-10 (2019).

22. Dong, G. et al. CMIP5 model-simulated onset, duration and intensity of the Asian summer monsoon in current and future climate. Clim. Dyn. 46, 355-382 (2016).

23. Kripalani, R. H., Oh, J. H., Kulkarni, A., Sabade, S. S. \& Chaudhari, H. S. South Asian summer monsoon precipitation variability: coupled climate model simulations and projections under IPCC AR4. Theor. Appl. Climatol. 90, 133-159 (2007).

24. Kripalani, R. H., Oh, J. H. \& Chaudhari, H. S. Response of the East Asian summer monsoon to doubled atmospheric $\mathrm{CO} 2$ : coupled climate model simulations and projections under IPCC AR4. Theor. Appl. Climatol. 87, 1-28 (2007).

25. Oh, H. \& Ha, K. J. Thermodynamic characteristics and responses to ENSO of dominant intraseasonal modes in the East Asian summer monsoon. Clim. Dyn. 44, 1751-1766 (2015).

26. Sooraj, K. P., Terray, P. \& Mujumdar, M. Global warming and the weakening of the Asian summer monsoon circulation: assessments from the CMIP5 models. Clim. Dyn. 45, 233-252 (2015).

27. Li, X., Ting, M., Li, C. \& Henderson, N. Mechanisms of Asian summer monsoon changes in response to anthropogenic forcing in CMIP5 models. J. Clim. 28, 4107-4125 (2015).

28. Hsu, P. C., Li, T., Murakami, H. \& Kitoh, A. Future change of the global monsoon revealed from 19 CMIP5 models. J. Geophys. Res. Atmos. 118, 1247-1260 (2013).

29. Chen, Z. et al. Global land monsoon precipitation changes in CMIP6 projections. Geophys. Res. Lett. 47, e2019GL086902 (2020).

30. Chadwick, R., Boutle, I. \& Martin, G. Spatial patterns of precipitation change in CMIP5: why the rich do not get richer in the tropics. J. Clim. 26, 3803-3822 (2013).

31. Akinsanola, A. A. \& Zhou, W. Projection of West African summer monsoon rainfall in dynamically downscaled CMIP5 models. Clim. Dyn. 53, 81-95 (2019).

32. Berg, A. et al. Land-atmosphere feedbacks amplify aridity increase over land under global warming. Nat. Clim. Change 6, 869-874 (2016).

33. Betts, R. A. et al. Projected increase in continental runoff due to plant responses to increasing carbon dioxide. Nature 448, 1037-1041 (2007).

34. Kumar, K. K. et al. The once and future pulse of Indian monsoonal climate. Clim Dyn. 36, 2159-2170 (2011).

35. Berg, P. \& Haerter, J. O. Unexpected increase in precipitation intensity with temperature-a result of mixing of precipitation types? Atmos. Res. 119, 56-61 (2013).

36. Park, I. H. \& Min, S. K. Role of convective precipitation in the relationship between subdaily extreme precipitation and temperature. J. Clim. 30, 9527-9537 (2017).
37. Lenton, T. M. et al. Tipping elements in the Earth's climate system. Proc. Natl Acad. Sci. USA 105, 1786-1793 (2008).

38. Lenton, T. M. et al. Climate tipping points-too risky to bet against. Nature $\mathbf{5 7 5}$, 592-595 (2019).

39. Xie, P. et al. GPCP pentad precipitation analyses: an experimental dataset based on Gauge observations and satellite estimates. J. Clim. 16, 2197-2214 (2003).

40. Dee, D. P. et al. The ERA-Interim reanalysis: configuration and performance of the data assimilation system. Q. J. R. Meteorol. Soc. 137, 553-597 (2011).

41. Seager, R., Naik, N. \& Vecchi, G. A. Thermodynamic and dynamic mechanisms for large-scale changes in the hydrological cycle in response to global warming. J. Clim. 23, 4651-4668 (2010)

\section{ACKNOWLEDGEMENTS}

This work was supported by the Institute for Basic Science under grant IBS-R028-D1. We acknowledge the providers of GPCP (https://precip.gsfc.nasa.gov/) and CMIP6 (https://esgf-node.IInl.gov/search/cmip6/) data.

\section{AUTHOR CONTRIBUTIONS}

K.-J.H. and S.M. designed the study; S.M. performed the analysis. All authors contributed to writing the manuscript.

\section{COMPETING INTERESTS}

The authors declare no competing interests.

\section{ADDITIONAL INFORMATION}

Supplementary information is available for this paper at https://doi.org/10.1038/ s41612-020-00151-w.

Correspondence and requests for materials should be addressed to K.-J.H.

Reprints and permission information is available at http://www.nature.com/ reprints

Publisher's note Springer Nature remains neutral with regard to jurisdictional claims in published maps and institutional affiliations.

Open Access This article is licensed under a Creative Commons Attribution 4.0 International License, which permits use, sharing, adaptation, distribution and reproduction in any medium or format, as long as you give appropriate credit to the original author(s) and the source, provide a link to the Creative Commons license, and indicate if changes were made. The images or other third party material in this article are included in the article's Creative Commons license, unless indicated otherwise in a credit line to the material. If material is not included in the article's Creative Commons license and your intended use is not permitted by statutory regulation or exceeds the permitted use, you will need to obtain permission directly from the copyright holder. To view a copy of this license, visit http://creativecommons. org/licenses/by/4.0/.

(c) The Author(s) 2020 